\title{
BMJ
}

\section{High frequency oscillation in patients with acute lung injury and acute respiratory distress syndrome (ARDS): systematic review and meta-analysis}

\author{
Sachin Sud, fellow, ${ }^{1}$ Maneesh Sud, medical student, ${ }^{2}$ an 0 Friedrich, assistant professor, ${ }^{3}$ Maureen O Meade, \\ associate professor, ${ }^{4}$ Niall D Ferguson, assistant professor, ${ }^{5}$ Hannah Wunsch, assistant professor, ${ }^{6}$ Neill K J \\ Adhikari, lecturer ${ }^{7}$
}

${ }^{1}$ Critical Care Medicine Program, Interdepartmental Division of Critical Care, University of Toronto, Toronto General Hospital, 585 University Ave, Toronto, ON, Canada, M5G 2N2

2Undergraduate Medicine Office, Faculty of Medicine 260 Brodie Centre, 727 McDermot Avenue, University of Manitoba, Winnipeg, MB, Canada, R3E 3P5

${ }^{3}$ Interdepartmental Division of Critical Care, University of

Toronto, and Critical Care and Medicine Departments and the Keenan Research Centre in the $\mathrm{L}$ Ka Shing Knowledge Institute, St Michael's Hospital, 30 Bond

Street, 4-015 Bond Wing, Toronto, ON, Canada, M5B 1W8

${ }^{4}$ Departments of Medicine and Clinical Epidemiology and

Biostatistics, McMaster University

Medical Centre, 1200 Main

Street W, Hamilton, Ontario,

Canada L8N $3 Z 5$

5 Interdepartmental Division of

Critical Care, University of

Toronto, and Department of

Medicine, Division of Respirology,

University Health Network and

Mount Sinai Hospital, 600

University Avenue, Suite 18-206,

Toronto, ON, Canada M5G 1X5

${ }^{6}$ Department of Anesthesiology,

Columbia University, 622 W 168th

St, PH5-527D, New York,

NY10032, USA

${ }^{7}$ Interdepartmental Division of

Critical Care, University of

Toronto, and Department of

Critical Care Medicine,

Sunnybrook Health Sciences

Centre, 2075 Bayview Avenue

Room D1.08, Toronto, ON, Canada M4N 3M5

Correspondence to: J 0 Friedrich

j.friedrich@utoronto.ca

Cite this as: $B M J$ J 2010;340:C2327 doi:10.1136/bmi.c2327

\section{ABSTRACT}

Objective To determine clinical and physiological effects of high frequency oscillation compared with conventional ventilation in patients with acute lung injury/acute respiratory distress syndrome (ARDS).

Design Systematic review and meta-analysis.

Data sources Electronic databases to March 2010, conference proceedings, bibliographies, and primary investigators.

Study selection Randomised controlled trials of high frequency oscillation compared with conventional ventilation in adults or children with acute lung injury/ ARDS.

Data selection Three authors independently extracted data on clinical, physiological, and safety outcomes according to a predefined protocol. We contacted investigators of all included studies to clarify methods and obtain additional data. Analyses used random effects models.

Results Eight randomised controlled trials ( $n=419$ patients) were included; almost all patients had ARDS. Methodological quality was good. The ratio of partial pressure of oxygen to inspired fraction of oxygen at 24 , 48 , and 72 hours was $16-24 \%$ higher in patients receiving high frequency oscillation. There were no significant differences in oxygenation index because mean airway pressure rose by $22-33 \%$ in patients receiving high frequency oscillation $(P \leq 0.01)$. In patients randomised to high frequency oscillation, mortality was significantly reduced (risk ratio $0.77,95 \%$ confidence interval 0.61 to 0.98, $\mathrm{P}=0.03$; six trials, 365 patients, 160 deaths), and treatment failure (refractory hypoxaemia, hypercapnoea, hypotension, or barotrauma) resulting in discontinuation of assigned therapy was less likely $(0.67,0.46$ to 0.99 , $\mathrm{P}=0.04$; five trials, 337 patients, 73 events). Other risks were similar. There was substantial heterogeneity between trials for physiological $\left(I^{2}=21-95 \%\right)$ but not clinical $\left(1^{2}=0 \%\right)$ outcomes. Pooled results were based on few events for most clinical outcomes.

Conclusion High frequency oscillation might improve survival and is unlikely to cause harm. As ongoing large multicentre trials will not be completed for several years, these data help clinicians who currently use or are considering this technique for patients with ARDS.

\section{INTRODUCTION}

Acute lung injury and acute respiratory distress syndrome (ARDS) are life threatening conditions characterised by acute lung inflammation causing pulmonary congestion, hypoxaemia, and decreased pulmonary compliance. Acute lung injury is common ${ }^{1}$ and is associated with substantial mortality, ${ }^{12}$ morbidity, ${ }^{34}$ and costs. ${ }^{5}$ Mechanical ventilation is usually required for adequate tissue oxygenation ${ }^{6}$ but might also perpetuate lung injury by overdistending and rupturing healthy alveoli and by triggering a secondary inflammatory response that intensifies lung injury from repeatedly opening and collapsing lung units. ${ }^{7-10}$ Lung protective ventilation seeks to limit alveolar distension, recruit non-aerated alveoli, and prevent further alveolar collapse. Although low tidal volumes with $^{11-14}$ or without ${ }^{15-17}$ high positive end expiratory pressure can reduce lung injury from ventilation, mortality in patients with ARDS remains high. ${ }^{12}$

High frequency oscillation is an alternative technique of ventilation in which small tidal volumes are delivered at high frequencies $(3-15 \mathrm{~Hz})$ with an oscillatory pump. ${ }^{18}$ High frequency oscillation theoretically meets the goals of a strategy of lung protective ventilation, ${ }^{19}$ with extremely small tidal volumes (1$4 \mathrm{ml} / \mathrm{kg}$ ) and constant lung recruitment. Although some centres increasingly use high frequency oscillation in patients with ARDS who do not tolerate conventional mechanical ventilation, ${ }^{20-22}$ its use other than as a "rescue" treatment remains controversial. ${ }^{2324} \mathrm{Sev}$ eral observational studies have shown improved oxygenation in patients with refractory hypoxaemia. ${ }^{25-27}$ An earlier systematic review of randomised controlled trials found only two small trials and could not draw definitive conclusions about the effect of high frequency oscillation on mortality. ${ }^{28}$ Additional studies have subsequently become available. Furthermore, in the context of current $\mathrm{t}^{2930}$ and future pandemics, there is a pressing need for evidence on the effects of 
Table 1 |Characteristics of populations of patients and risk of bias ${ }^{40}$ in trials included in systematic review

\begin{tabular}{|c|c|c|c|c|c|c|}
\hline & No of patients & $\begin{array}{l}\text { Mean age } \\
\text { (years) }\end{array}$ & Setting & $\begin{array}{l}\text { Days of ventilation } \\
\text { before study }\end{array}$ & Details of lung injury & Overall risk of bias* \\
\hline Arnold et al, ${ }^{48} 1994$ & 70 (weight $\leq 35 \mathrm{~kg}$ ) & 2.8 & 5 US paediatric ICUs & $4.5 \dagger$ & $\begin{array}{l}\text { ARDS ( } 86 \%) \text { or pulmonary barotrauma } \\
\text { requiring chest tube }(14 \%)\end{array}$ & $\begin{array}{l}\text { Unclear ( }>10 \% \text { ( } 30 / 58) \text { crossovers; } \\
\text { outcome data for } 12 / 70 \text { patients not } \\
\text { available after author contact) }\end{array}$ \\
\hline Derdak et al, ${ }^{51} 2002$ & 148 & 49 & $\begin{array}{l}\text { ICUs in } 13 \text { US } \\
\text { hospitals }\end{array}$ & $1.9 \dagger$ & ARDS; PEEP >10 $\mathrm{cm} \mathrm{H}_{2} \mathrm{O}$ & Low \\
\hline Shah et al, ${ }^{55} 2004 \ddagger$ & 28 & 49 & $1 \mathrm{ICU}$ in Cardiff & $<5$ & ARDS & Low \\
\hline Bollen et $\mathrm{al}^{49}{ }^{49} 2005$ & 61 & 53 & $\begin{array}{l}5 \text { ICUs in } 4 \text { European } \\
\text { cities }\end{array}$ & $1.8 \dagger$ & ARDS & $\begin{array}{l}\text { Unclear ( }>10 \% \text { (11/61) crossovers; ICU } \\
\text { but not } 30 \text { day mortality available for } 3 / \\
61 \text { patients after author contact; trial } \\
\text { terminated early because of slow } \\
\text { recruitment) }\end{array}$ \\
\hline $\begin{array}{l}\text { Papazian et al, }{ }^{53} \\
2005\end{array}$ & 26 & 51 & $\begin{array}{l}1 \mathrm{ICU} \text { in Marseille, } \\
\text { France }\end{array}$ & $\ll 1$ (duration of ARDS $<24 \mathrm{~h}$ ) & ARDS; $\mathrm{PaO}_{2} / \mathrm{FiO}_{2} \leq 150, \mathrm{PEEP} \geq 5 \mathrm{~cm} \mathrm{H}_{2} \mathrm{O}$ & Low \\
\hline $\begin{array}{l}\text { Samransamruajkit et } \\
\text { al, }^{54} 2005\end{array}$ & 16 (weight $\leq 35 \mathrm{~kg}$ ) & 5 & $\begin{array}{l}1 \text { ICU in Bangkok, } \\
\text { Thailand }\end{array}$ & $<2$ (duration of ARDS $<48 \mathrm{~h}$ ) & $\begin{array}{l}\text { ARDS, PEEP }>5 \mathrm{~cm} \mathrm{H}_{2} \mathrm{O} ; \mathrm{FiO}_{2}>0.6 \text { for } 12 \mathrm{~h} \\
\text { to keep } \mathrm{SaO}_{2}>92 \% \text {; Ol }>15 \text { for } \geq 4 \mathrm{~h}\end{array}$ & Low \\
\hline Demory et $\mathrm{al}^{50} 2007$ & 28 & 49 & $\begin{array}{l}1 \mathrm{ICU} \text { in Marseille, } \\
\text { France }\end{array}$ & $\ll 1$ (duration of ARDS $<24 \mathrm{~h}$ ) & ARDS; $\mathrm{PaO}_{2} / \mathrm{FiO}_{2}<150, \mathrm{PEEP} \geq 5 \mathrm{~cm} \mathrm{H}_{2} \mathrm{O}$ & Low \\
\hline $\begin{array}{l}\text { Mentzelopoulos et } \\
\mathrm{al}^{52} 2007 \ddagger\end{array}$ & 54 & 57 & $\begin{array}{l}1 \mathrm{ICU} \text { in Athens, } \\
\text { Greece }\end{array}$ & $3.5 \dagger$ & ARDS; $\mathrm{PaO}_{2} / \mathrm{FiO}_{2}<150$, PEEP $8 \mathrm{~cm} \mathrm{H} \mathrm{H}_{2} \mathrm{O}$ & Low \\
\hline
\end{tabular}

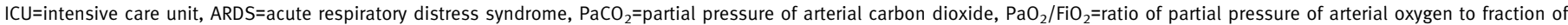
inspired oxygen, $\mathrm{PEEP}=$ positive end expiratory pressure, $\mathrm{SaO}_{2}=$ oxygen saturation, Ol=oxygenation index.

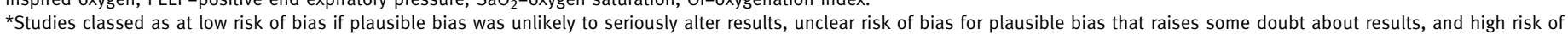
bias for plausible bias that seriously weakens confidence in results. None of the included studies was blinded, and all studies reported adequate sequence generation, adequate

concealment of allocation, and were free from selective outcome reporting.

†Mean.

$\ddagger$ Conference abstracts, with supplementary information provided by primary investigators.

potentially life saving interventions for patients with ARDS. Although large randomised trials of high frequency oscillation are under way, they will not be completed for several years. We therefore performed a systematic review and meta-analysis of randomised controlled trials of high frequency oscillation compared with conventional mechanical ventilation for adults and children with acute lung injury and ARDS to determine effects on mortality, other clinical and physiological outcomes, and adverse events.

\section{METHODS}

We developed a systematic review protocol with prespecified criteria for study selection, outcome measurements, and analysis.

\section{Study identification}

We used systematic methods to identify published and unpublished randomised controlled trials of high frequency oscillation compared with conventional mechanical ventilation in patients with acute lung injury, ARDS, or other forms of hypoxaemic respiratory failure. ${ }^{31}$ To identify all relevant trials, we electronically searched Medline, Embase, CENTRAL, and ISI (from inception to March 2010, see appendix 1 on bmj.com); manually searched reference lists from included studies and review articles; searched conference proceedings of the American Thoracic Society (1994-2009), Society of Critical Care Medicine (19942010), European Society of Intensive Care Medicine (1994-2009), and American College of Chest Physicians (1994-2009); contacted clinical experts in the specialty; and searched for unpublished and ongoing trials in clinicaltrials.gov and controlled-trials.com. There were no language restrictions. $^{32}$

\section{Study eligibility}

Two investigators (SS, MS), not blinded to study authors or results, ${ }^{33}$ independently evaluated eligibility of studies and resolved differences by consensus. To be included studies had to enrol adults or children (aged over 4 weeks and over 42 weeks after conception) with acute lung injury or ARDS who were receiving conventional mechanical ventilation; assign patients randomly to two or more groups, including an experimental group that received high frequency oscillation

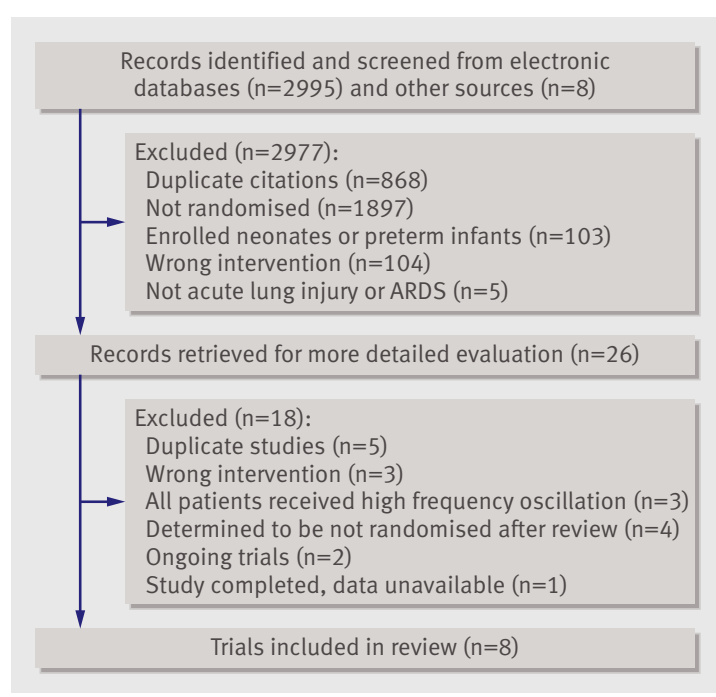

Fig 1| Flow of studies included in review 
Table 2 |Details of high frequency oscillation (HFO) and conventional mechanical ventilation (CMV) in trials included in systematic review

\begin{tabular}{|c|c|c|c|c|c|c|c|c|c|}
\hline & \multicolumn{5}{|c|}{ High frequency oscillation } & \multicolumn{4}{|c|}{ Conventional ventilation } \\
\hline & $\begin{array}{l}\text { Frequency } \\
(\mathrm{Hz})\end{array}$ & $\begin{array}{c}\text { Mean Paw (cm } \\
\mathrm{H}_{2} \mathrm{O} \text { above } \\
\left.{ }_{\mathrm{CMV}}\right)\end{array}$ & $\begin{array}{c}\Delta \mathrm{P}\left(\mathrm{cm} \mathrm{H}_{2} \mathrm{O}\right) \\
\text { titration } \\
\text { parameter or goal }\end{array}$ & $\begin{array}{l}\text { Recruitment } \\
\text { manoeuvre } \\
\text { protocol }\end{array}$ & $\begin{array}{l}\text { Criteria for } \\
\text { transition to } \\
\text { CMV }\end{array}$ & Mode & Tidal volume & $\begin{array}{l}\text { Adjustment of } \\
\text { PEEP }\left(\mathrm{cm} \mathrm{H}_{2} \mathrm{O}\right)\end{array}$ & $\begin{array}{c}\text { Recruitment } \\
\text { manoeuvre } \\
\text { protocol }\end{array}$ \\
\hline $\begin{array}{l}\text { Arnold et al, } \\
1994\end{array}$ & $5-10$ & 4-8 & $\begin{array}{l}\text { Achieve chest wall } \\
\text { vibration or } \\
\text { according to } \\
\text { transcutaneous } \\
\mathrm{PCO}_{2} \text { sensor }\end{array}$ & No & $\begin{array}{l}\text { Mean Paw } 18 \mathrm{~cm} \\
\mathrm{H}_{2} \mathrm{O} \text {, tolerating } \\
\text { suctioning }\end{array}$ & Pressure limited & NR & $\begin{array}{l}\text { Clinician } \\
\text { discretion }\end{array}$ & No \\
\hline $\begin{array}{l}\text { Derdak et al, } \\
2002\end{array}$ & 5 & 5 & $\begin{array}{l}\text { Achieve vibration } \\
\text { from chest wall to } \\
\text { mid-thigh }\end{array}$ & No & $\begin{array}{l}\mathrm{FiO}_{2}<50 \%, \\
\text { mean Paw }<24 \\
\mathrm{~cm} \mathrm{H}_{2} \mathrm{O}\end{array}$ & Pressure control & $\begin{array}{l}6-10 \mathrm{ml} / \mathrm{kg} \\
\text { actual body } \\
\text { weight }\end{array}$ & $\begin{array}{l}\text { 10-18, by } \\
\text { protocol }\end{array}$ & No \\
\hline $\begin{array}{l}\text { Shah et al, } \\
2004 \ddagger\end{array}$ & 5 & 5 & $\begin{array}{l}\text { Achieve vibration } \\
\text { from chest wall to } \\
\text { mid-thigh }\end{array}$ & No & $\begin{array}{c}\text { Until resolution } \\
\text { of ARDS }\end{array}$ & NR & $\begin{array}{l}\text { Mean } 7-8 \mathrm{ml} / \mathrm{kg} \\
\text { ideal body } \\
\text { weight* }\end{array}$ & NR & No \\
\hline $\begin{array}{l}\text { Bollen et al, }{ }^{49} \\
2005\end{array}$ & 5 & 5 & $\begin{array}{l}\text { According to } \\
\mathrm{PaCO}_{2} ; \text { achieve } \\
\text { chest wall vibration }\end{array}$ & No & $\begin{array}{c}\mathrm{FiO}_{2}<40 \%, \mathrm{PaO}_{2} \\
>60 \mathrm{~mm} \mathrm{Hg}, \\
\text { tolerating } \\
\text { suctioning }\end{array}$ & Pressure control & $\begin{array}{l}\text { Mean } 8-9 \mathrm{ml} / \mathrm{kg} \\
\text { ideal body } \\
\text { weight† }\end{array}$ & NR & No \\
\hline $\begin{array}{l}\text { Papazian et al, }{ }^{53} \\
2005\end{array}$ & 5 & 5 & $\begin{array}{l}\text { Same } \mathrm{PaCO}_{2} \text { as } \\
\text { during } \mathrm{CMV}_{\text {(max. }} \\
110)\end{array}$ & At HFO initiation & $\begin{array}{l}\text { After } 12 \text { hours of } \\
\text { HFO }\end{array}$ & $\begin{array}{l}\text { Volume assist } \\
\text { control }\end{array}$ & $\begin{array}{l}6 \mathrm{ml} / \mathrm{kg} \text { ideal } \\
\text { body weight }\end{array}$ & $\begin{array}{l}2 \text { above lower } \\
\text { inflection point }\end{array}$ & No \\
\hline $\begin{array}{l}\text { Samransamruaj- } \\
\text { kit et al, }{ }^{54} 2005\end{array}$ & 4-10 & $2-3$ & $\begin{array}{l}10 \text { above peak } \\
\text { inspiratory } \\
\text { pressure during } \\
\text { CMV }\end{array}$ & No & $\begin{array}{l}\text { Mean Paw } 18 \mathrm{~cm} \\
\mathrm{H}_{2} \mathrm{O} \text {, tolerating } \\
\text { suctioning }\end{array}$ & $\begin{array}{l}\text { Time cycled or } \\
\text { pressure control }\end{array}$ & $\begin{array}{l}\text { 6-7 } \mathrm{ml} / \mathrm{kg} \text { ideal } \\
\text { body weight }\end{array}$ & $\begin{array}{l}\text { According to } \\
\text { ARDS Network } \\
\text { protocol }^{15}\end{array}$ & No \\
\hline $\begin{array}{l}\text { Demory et al, } \\
2007\end{array}$ & 5 & $\begin{array}{l}5 \text { higher but } \\
\text { SPplat }\end{array}$ & $\begin{array}{l}\text { Same } \mathrm{PaCO}_{2} \text { as } \\
\text { during } \mathrm{CMV}_{\text {(max }} \\
110)\end{array}$ & At HFO initiation & $\begin{array}{l}\text { After } 12 \text { hours of } \\
\text { HFO }\end{array}$ & $\begin{array}{l}\text { Volume assist } \\
\text { control }\end{array}$ & $\begin{array}{l}6-7 \mathrm{ml} / \mathrm{kg} \\
\text { predicted body } \\
\text { weight }\end{array}$ & $\begin{array}{l}\text { According to } \\
\text { ARDS Network } \\
\text { protocol }^{15}\end{array}$ & No \\
\hline $\begin{array}{l}\text { Mentzelopoulos } \\
\text { et al, }{ }^{52} 2007 \ddagger\end{array}$ & 4 & $\begin{array}{l}3 \text { above mean } \\
\text { tracheal } \\
\text { pressure } \\
\text { measured distal } \\
\text { to endotracheal } \\
\text { tube }\end{array}$ & $\begin{array}{l}30 \text { above baseline } \\
\mathrm{PaCO}_{2} \text { during } \mathrm{CMV}\end{array}$ & $\begin{array}{l}\text { Throughout HFO } \\
\text { administration }\end{array}$ & $\begin{array}{l}\text { After } 6-24 \mathrm{~h} \text { of } \\
\mathrm{HFO} \text { each day } \\
\text { until } \mathrm{PaO}_{2} / \mathrm{FiO}_{2} \\
\geq 150 \text { for }>12 \mathrm{~h} \text { on } \\
\text { CMV }\end{array}$ & $\begin{array}{l}\text { Volume assist } \\
\text { control }\end{array}$ & $\begin{array}{l}6-7 \mathrm{ml} / \mathrm{kg} \\
\text { predicted body } \\
\text { weight }\end{array}$ & $\begin{array}{l}\text { According to } \\
\text { ARDS Network } \\
\text { protocol }^{15}\end{array}$ & Yes \\
\hline
\end{tabular}

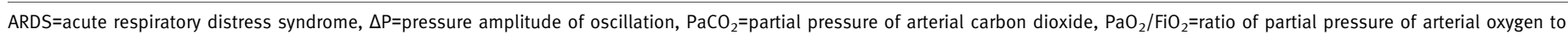
fraction of inspired oxygen, Paw=airway pressure, $\mathrm{PEEP}=$ positive end expiratory pressure, Pplat = plateau pressure, $N R=$ not reported.

${ }^{\star}$ Calculated from mean tidal volume and mean ideal body weight on days 1 , 2, and 3; tidal volume adjusted according to ARDS Network low tidal volume protocol. ${ }^{15}$

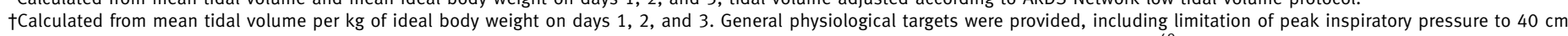
$\mathrm{H}_{2} \mathrm{O}$, but "more detailed ventilation procedures and methods of weaning were according to standard protocols of the investigating centres." ${ }^{49}$

$\ddagger$ Conference abstracts, with supplementary information provided by primary investigators.

and a control group that received conventional mechanical ventilation; and report any of our primary or secondary outcomes. For analyses of clinical out comes, we included trials if patients were allocated to high frequency oscillation or conventional mechanical ventilation as the primary ventilation strategy until resolution of acute lung injury or ARDS. We included trials that enrolled both adults and children because we believed that the physiological benefits of lung recruitment and reduction in tidal volume that occur during high frequency oscillation would be similar for both adult and paediatric ARDS. ${ }^{154-36}$ We also included trials in which a secondary intervention was delivered as part of high frequency oscillation, such as tracheal gas insufflation or recruitment manoeuvres, as some centres apply these in association with high frequency oscillation. We included trials in which the duration of high frequency oscillation was 24 hours or less for physiological outcome analyses but excluded them from analyses of clinical outcomes.

We accepted authors' definitions of acute lung injury and ARDS. In trials that enrolled patients with other forms of respiratory failure, we stipulated that a minimum of $70 \%$ of patients must have acute lung injury or
ARDS to meet inclusion criteria. We excluded crossover trials, in which all patients experience treatment and control interventions in random order.

\section{Data extraction and study quality}

Three reviewers (SS, MS, JOF) used a standardised spreadsheet to independently abstract data on study methods, details of ventilation strategies, and study outcomes. Disagreements remaining after contact with authors were resolved by consensus.

We abstracted data on methods of randomisation and allocation concealment, ${ }^{37}$ number of withdrawals after randomisation and losses to follow-up, crossovers between assigned groups, blinding of outcome assessors, ${ }^{38}$ and early stopping for benefit. ${ }^{39}$ We summarised the risk of bias for individual studies using a modified version of the Cochrane Collaboration risk of bias instrument. ${ }^{40}$ As blinding of care givers, patients, and family members is impossible in these trials, we determined whether important co-interventions (weaning, sedation, and paralysis) and use of rescue treatments for refractory respiratory failure (inhaled nitric oxide, prone positioning, steroids, and extracorporeal oxygenation) were standardised or 
Table 3 |Additional interventions or rescue treatments and funding in trials of high frequency oscillation and conventional mechanical ventilation included in systematic review

\begin{tabular}{|c|c|c|c|c|c|}
\hline & High frequency oscillation & $\begin{array}{l}\text { Conventional mechanical } \\
\text { ventilation }\end{array}$ & $\begin{array}{l}\text { Sedation and paralysis applied } \\
\text { equally to both groups }\end{array}$ & $\begin{array}{l}\text { Protocols for ventilator } \\
\text { weaning and extubation }\end{array}$ & $\begin{array}{l}\text { Funding* } \\
\text { (industry support) }\end{array}$ \\
\hline Arnold et al, ${ }^{48} 1994$ & NR & NR & No & NR & Yes \\
\hline Derdak et al, ${ }^{51} 2002$ & $\begin{array}{l}\text { Nitric oxide, } 4 / 75 \text {; prone } \\
\text { position, } 2 / 75 \text {, high dose } \\
\text { steroids, } 1 / 75\end{array}$ & $\begin{array}{l}\text { Nitric oxide, } 8 / 73 ; \text { prone } \\
\text { position, } 3 / 73 ; \text { high dose } \\
\text { steroids, } 4 / 73\end{array}$ & No & No & Yes \\
\hline Shah et al, ${ }^{55} 2004 \dagger$ & None & None & Yes & NR & No \\
\hline Bollen et al, ${ }^{49} 2005$ & NR & NR & NR & No & Yes \\
\hline Papazian et al, ${ }^{53} 2005$ & $\begin{array}{l}\text { All patients ventilated in } \\
\text { prone position }\end{array}$ & $\begin{array}{l}\text { All patients ventilated in } \\
\text { prone position }\end{array}$ & Yes & No & No \\
\hline $\begin{array}{l}\text { Samransamruajkit et al, }{ }^{54} \\
2005\end{array}$ & Nitric oxide, $1 / 7$ & Nitric oxide, $0 / 9$ & Yes & No & No \\
\hline Demory et al, ${ }^{50} 2007$ & $\begin{array}{l}\text { Prone position for } 12 \mathrm{~h} \text { before } \\
\text { HFO in supine position }\end{array}$ & $\begin{array}{l}\text { Prone position for } 12 \mathrm{~h} \text { prior to } \\
\mathrm{CMV} \text { in supine position }\end{array}$ & Yes & No & No \\
\hline Mentzelopoulos et al, ${ }^{52} 2007 \ddagger$ & $\begin{array}{l}\text { All patients received tracheal } \\
\text { gas insufflation. Steroids for } \\
\text { ARDS, } 20 / 27\end{array}$ & Steroids for ARDS, $21 / 27$ & $\begin{array}{l}\text { No }(27 / 27 \text { HFO } v 17 / 27 \text { CMV } \\
\text { patients paralysed) }\end{array}$ & Yes & No \\
\hline
\end{tabular}

NR=not reported, ARDS=acute respiratory distress syndrome.

*Industry funding (CareFusion, formerly Sensor Medics) included partial support of study or provision of Sensor Medics $3100 \mathrm{~B}$ HFO ventilators.

†Conference abstracts, with supplementary information provided by primary investigators.

equally applied in treatment groups. We assessed the quality of evidence for clinical outcomes, including mortality, treatment failure, and adverse events, according to recommendations of the GRADE working group. ${ }^{41}$

We contacted authors of all included trials to request additional data and to clarify methods as necessary.

\section{Outcomes}

We considered the following clinical outcomes: hospital or 30 day mortality (primary outcome), six month mortality, duration of mechanical ventilation, ventilator-free days to day 28 or 30 , health related quality of life at one year, and treatment failure leading to crossover to the other arm or discontinuation of the study protocol (secondary outcomes). We accepted authors' definitions of treatment failure, which could include severe oxygenation failure, ventilation failure, hypotension, or barotrauma (pneumothorax, pneumomediastinum, subcutaneous emphysema). We also considered physiological outcomes measured at 24 , 48 , and 72 hours after randomisation: oxygenation, measured by the ratio of partial pressure of arterial

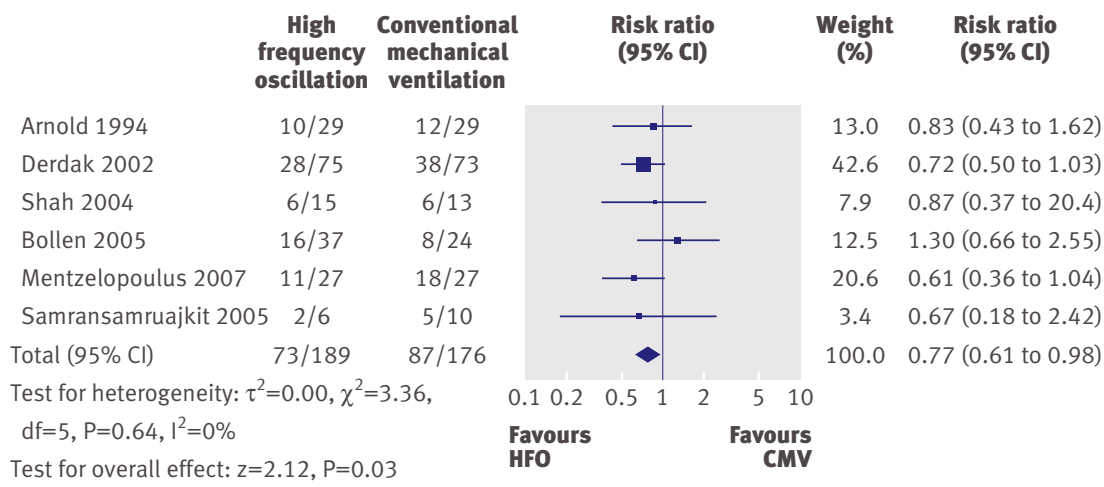

Fig 2 | Hospital or 30 day mortality in patients with acute lung injury/acute respiratory distress syndrome allocated to high frequency oscillation or conventional mechanical ventilation oxygen $\left(\mathrm{PaO}_{2}\right)$ to inspired fraction of oxygen $\left(\mathrm{FiO}_{2}\right)$ $\left(\mathrm{PaO}_{2} / \mathrm{FiO}_{2}\right.$ ratio); oxygenation index (OI, defined as $100 \times$ mean airway pressure $/\left(\mathrm{PaO}_{2} / \mathrm{FiO}_{2}\right.$ ratio $\left.)\right)$; ventilation, measured by partial pressure of carbon dioxide $\left(\mathrm{PaCO}_{2}\right)$; and mean airway pressure. Finally, we considered adverse events including barotrauma, hypotension, obstruction of endotracheal tube from secretions, and technical complications and equipment failure in patients treated with high frequency oscillation (including unintentional system air leaks and problems with the oscillatory diaphragm, humidifier, and alarm systems). ${ }^{2142}$

Whenever possible, we analysed patients according to their randomly assigned group for all clinical and physiological outcomes.

\section{Statistical analysis}

We conducted meta-analyses using random effects models in Review Manager (RevMan) 5.0 (Cochrane Collaboration, 2008) and statistical tests of publication bias using the metabias command in Stata 9.2 (2006 StataCorp, College Station, TX). Random effects models incorporate variation both within and between studies and typically provide wider confidence intervals when heterogeneity is present. We reported continuous outcomes using weighted mean difference (a measure of absolute change) or ratio of means (a measure of relative change $)^{43}$ and binary outcomes as risk ratios. We considered (two sided) $\mathrm{P}<0.05$ as significant and reported individual trial and summary results with 95\% confidence intervals.

We assessed heterogeneity between studies for each outcome using the $\mathrm{I}^{2}$ measure ${ }^{4445}$ and used published guidelines for low $\left(\mathrm{I}^{2}=25-49 \%\right)$, moderate $\left(\mathrm{I}^{2}=50-74 \%\right)$, and high $\left(\mathrm{I}^{2} \geq 75 \%\right)$ heterogeneity. ${ }^{45}$

To assess publication bias we examined funnel plots of treatment effect versus study precision and used Begg's rank correlation test ${ }^{46}$ and a modified Macaskill's regression test. ${ }^{47}$ Given the low statistical power 
Table 4 |Clinical outcomes and adverse events in trials of high frequency oscillation

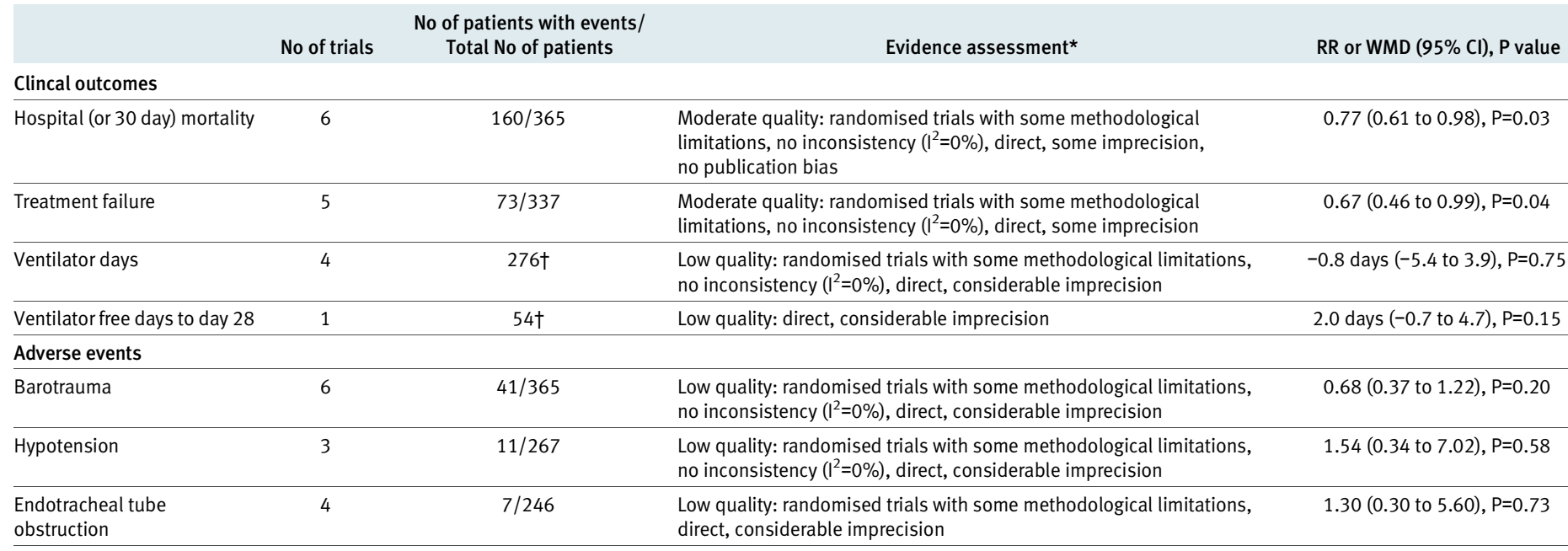

$\mathrm{RR}=$ relative risk; $\mathrm{WMD}=$ weighted mean difference.

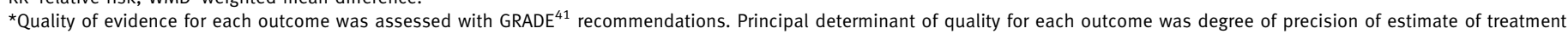

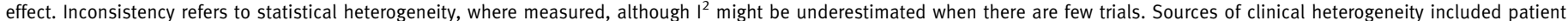

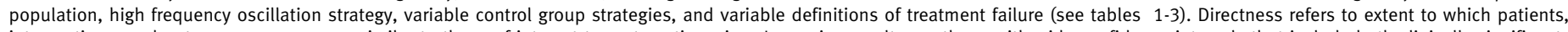

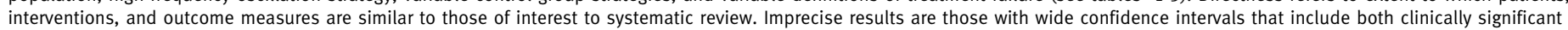
benefit and harm. Publication bias was assessed for mortality only.

†Total No of patients.

of these tests, we assumed a more liberal level of significance $(\mathrm{P}<0.10)$ to indicate possible publication bias.

\section{Subgroup analyses}

We prespecified subgroup analyses (based on patient's age (adult $v$ paediatric) and risk of bias of the trial (low $v$ high or unclear) (see also appendix 2 on bmj.com) to explore potential heterogeneity for the primary outcome of hospital or 30 day mortality and to assess consistency of results between important subgroups. We also conducted a post hoc analysis of the effect of high frequency oscillation on hospital or 30 day mortality in trials that mandated tidal volumes $\leq 8 \mathrm{ml} / \mathrm{kg}$ of predicted or ideal body weight in the control group compared with those that permitted higher tidal volumes. We assessed whether differences between subgroups were significant using a $\mathrm{z}$ test for interaction.

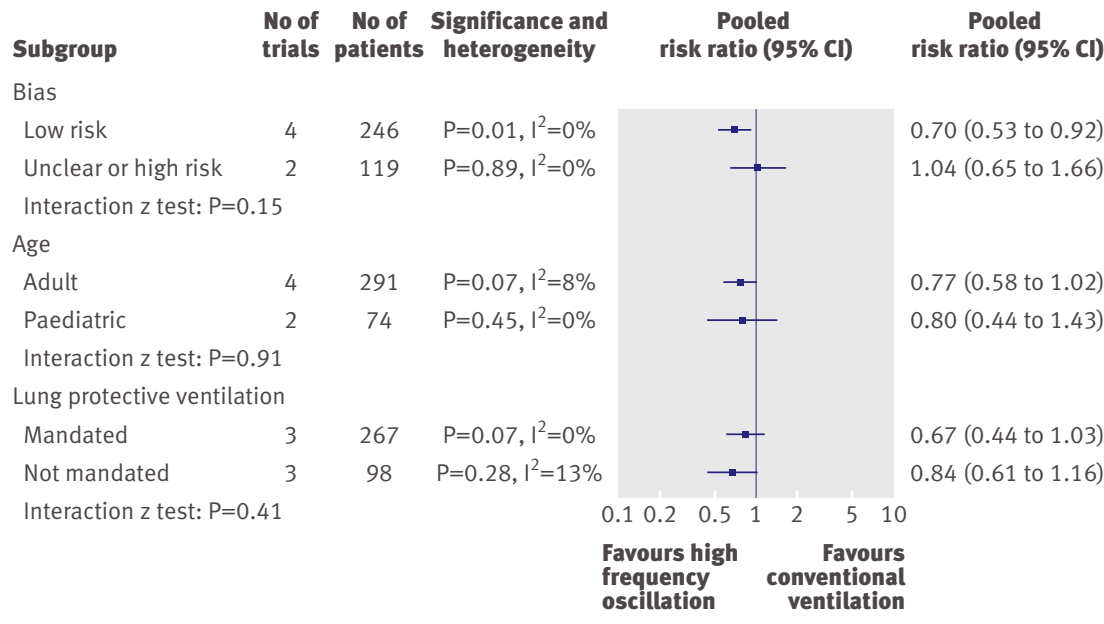

Fig 3 Subgroup analyses based on age of patients, risk of bias, and use of lung protective ventilation in control groups

\section{RESULTS}

\section{Literature search}

We identified 2995 citations from searches of electronic bibliographic databases and eight original citations from other sources. We retrieved 26 studies for detailed evaluation, of which eight trials ${ }^{48-55}$ met criteria for this review (fig 1). Details of excluded studies are in appendix 1 on bmj.com. Reviewers agreed on all studies for inclusion. Primary investigators provided additional clinical $^{50-55}$ or physiological ${ }^{51525455}$ data or clarified data or methods. ${ }^{48-55}$

\section{Study characteristics and quality of methods}

The eight included trials ${ }^{48-55}$ enrolled a total of 431 patients (median 41, range 16-148) with acute lung injury and ARDS (tables 1-3). Seven trials ${ }^{49-55}$ enrolled patients exclusively with ARDS ( $\mathrm{n}=361$ ), and $86 \%$ $(n=52)$ of the patients in the eighth trial had ARDS. ${ }^{48}$ Two trials enrolled only children. ${ }^{4854}$ Two trials are currently published only as abstracts. ${ }^{5255}$ All trials studied high frequency oscillation as an initial ventilation strategy for acute lung injury or ARDS, as opposed to rescue treatment for refractory hypoxaemia. Trials enrolled patients within 48 hours of diagnosis of ARDS $^{505354}$ or shortly after initiation of mechanical ventilation (mean of less than two days ${ }^{4951}$ or five days ${ }^{4855}$ ). All trials treated patients continuously with high frequency oscillation except for one that applied high frequency oscillation by protocol for 6-24 hours a day until predefined criteria for resolution of severe ARDS had been met (most patients were treated for at least four days). ${ }^{52}$ In two trials patients were treated for $<24$ hours. ${ }^{5053}$ The median baseline $\mathrm{PaO}_{2} / \mathrm{FiO}_{2}$ ratio was 112 (range 80-122) in seven trials. ${ }^{48-5153-55}$ All studies implemented high frequency oscillation according to a protocol and described conventional 


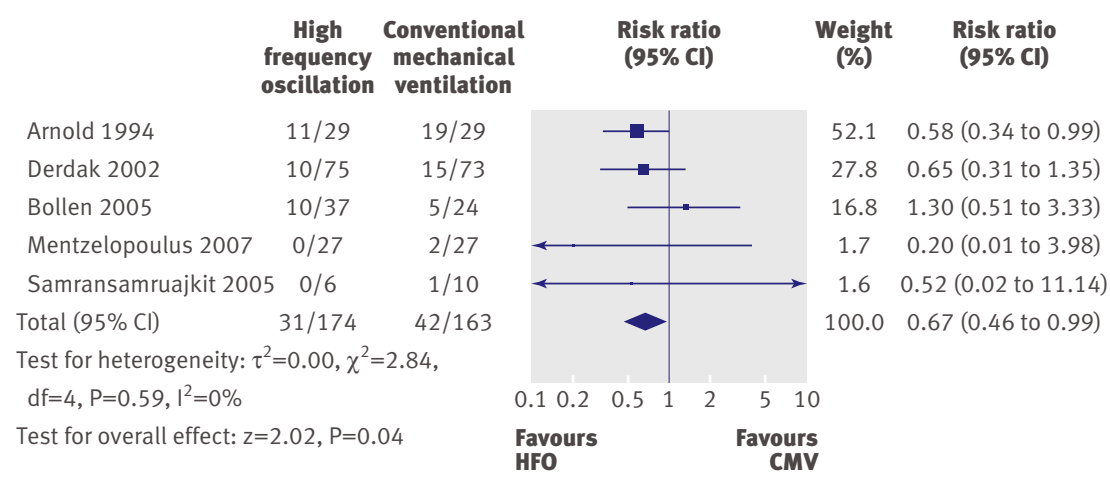

Fig 4 | Treatment failure in patients with acute lung injury/acute respiratory distress syndrome allocated to high frequency oscillation or conventional mechanical ventilation

mechanical ventilation (table 2, and appendix 2 on bmj.com). Five trials mandated low tidal volume ventilation $(\leq 8 \mathrm{ml} / \mathrm{kg})$ in the control group, ${ }^{5052-55}$ and four trials mandated plateau pressure $<35 \mathrm{~cm} \mathrm{H}_{2} \mathrm{O} .^{5053-55}$

Six trials had high methodological quality and a low risk of bias. ${ }^{50-55}$ The risk of bias was unclear in two studies. ${ }^{4849}$ All trials concealed allocation and analysed clinical outcomes for patients by assigned group ${ }^{48-5355}$ or provided enough information to perform analyses according to assigned group. ${ }^{54}$ One trial was terminated early because of low recruitment. ${ }^{49}$ Six trials reported no withdrawals after randomisation ${ }^{49} 50$ 52-55; in two trials, $1.4 \%(2 / 148)^{51}$ and $17 \%(12 / 70)^{48}$ of patients were withdrawn after randomisation. After contacting investigators, we obtained mortality data for withdrawn patients in one trial. ${ }^{51}$ There was no loss to follow-up in seven studies. ${ }^{480-55}$ One study provided mortality data from intensive care only, but not 30 day mortality, for $5 \%(3 / 61)$ of patients. ${ }^{49}$ Five trials reported crossovers between groups (range 4-52\% of all randomised patients), ${ }^{4849515254}$ which involved 0$19 \%$ of patients randomised to high frequency oscillation $\left(7 / 37,{ }^{49} 11 / 29,{ }^{48} 0 / 6,{ }^{54} 0 / 27,{ }^{52}\right.$ and $\left.4 / 75^{51}\right)$ and 7 $65 \%$ of patients randomised to conventional ventilation $\left(4 / 24,{ }^{49} 19 / 29,{ }^{48} 1 / 10,{ }^{54} 2 / 27,{ }^{52}\right.$ and $\left.9 / 73^{51}\right)$.

\section{Clinical outcomes}

Table 4 summarises the clinical outcomes.

\section{Mortality}

In the primary analysis including six trials that treated patients with high frequency oscillation until resolution of $\mathrm{ARDS}^{484951525455}$ ( $\left.\mathrm{n}=365\right)$, the median hospital or 30 day mortality in the control group was $48 \%$ (range 33-67\%). High frequency oscillation significantly reduced mortality at hospital discharge ${ }^{5254}$ or 30 days $^{48} 495155$ (risk ratio $0.77,95 \%$ confidence interval 0.61 to $0.98, \mathrm{P}=0.03$; fig 2 ). In one trial, $3 / 61$ patients were alive at discharge from the intensive care unit and assumed to be alive at 30 days; censoring these patients does not alter the results of the meta-analysis $(0.77$, 0.61 to $0.98, \mathrm{P}=0.04$ ). Subgroup analyses (fig 3) did not show significant differences in treatment effect among four trials in adults ${ }^{49515255}(\mathrm{n}=291)$ compared with two trials in children ${ }^{4854}(\mathrm{n}=74)(\mathrm{P}=0.91$ for interaction $\mathrm{z}$ test) or four trials $(\mathrm{n}=246)$ at low ${ }^{51525455}$ compared with two trials $(\mathrm{n}=119)$ at high or unclear $^{4849}$ risk of bias $(\mathrm{P}=0.15$ for interaction $\mathrm{z}$ test). In a post hoc analysis (fig 3), there was no significant difference in treatment effect among three trials ${ }^{5254} 55$ $(\mathrm{n}=98)$ that mandated tidal volumes $\leq 8 \mathrm{ml} / \mathrm{kg}$ in the control group and three trials ${ }^{484951}(n=267)$ that allowed higher tidal volumes ( $\mathrm{z}$ test for interaction, $\mathrm{P}=0.41$, fig 3$)$. Only one trial ${ }^{51}(\mathrm{n}=148)$ reported mortality at six months, with no significant effect of high frequency oscillation $(0.79,0.58$ to $1.08, \mathrm{P}=0.14)$. No trial reported on health related quality of life.

There was no evidence of publication bias. Visual inspection of a funnel plot showed no asymmetry, and neither Begg's rank correlation test $(\mathrm{P}=0.45)$ nor Macaskill's regression test $(\mathrm{P}=0.94)$ was significant.

Treatment failure and duration of mechanical ventilation In five trials $(n=337)$ high frequency oscillation reduced the risk of treatment failure compared with conventional mechanical ventilation (risk ratio 0.67 , 0.46 to $0.99, \mathrm{P}=0.04$; fig 4). ${ }^{4849515254}$ Three trials $(\mathrm{n}=267)$ reported treatment failure according to predefined criteria (oxygenation failure, ventilation failure, hypotension, or barotrauma) that resulted in discontinuation of the assigned ventilation strategy. ${ }^{484951}$ Two trials $(n=70)$ did not report this outcome, but we obtained data directly from the authors. ${ }^{5254}$ In one trial, one patient randomised to conventional ventilation with early treatment failure who crossed over to high frequency oscillation because of barotrauma was analysed as treatment failure in the conventional mechanical ventilation group. ${ }^{54}$ If two patients randomised to conventional ventilation in another trial ${ }^{52}$ who crossed over to high frequency oscillation for only three and six hours are not counted as treatment failures, the pooled result is no longer significant $(0.69$, 0.46 to $1.01, \mathrm{P}=0.06$ ). No trial reported blinding of outcome assessors or independent adjudication of treatment failure.

Neither the duration of mechanical ventilation (mean difference -0.8 days, -5.4 to 3.9 days, $\mathrm{P}=0.75$; four trials, ${ }^{4515254} \mathrm{n}=276$, see fig A5 in appendix 2 on bmj.com) nor ventilator-free days to day 28 (2.0 days, -0.7 to 4.7 days, $\mathrm{P}=0.15$; one trial, ${ }^{52} \mathrm{n}=54$ ) significantly differed between groups.

There was no evidence of heterogeneity $\left(\mathrm{I}^{2}=0 \%\right)$ for any clinical outcome.

\section{Physiological outcomes}

Table 5 and figure 5 summarise the physiological outcomes. Further details are in appendix 2 on bmj.com. Figure 5 shows the results for $\mathrm{PaO}_{2} / \mathrm{FiO}_{2}$ ratio in days 1,2 , and 3. Day 1 measurements were obtained at 24 hours, except in two studies where they were obtained at 12 hours. ${ }^{5053}$ Analyses are by intention to treat except for one patient in one trial, ${ }^{54}$ who crossed over from conventional ventilation to high frequency oscillation shortly after randomisation and was analysed as treated because we were unable to obtain sufficient data (after contacting the author) to permit an intention 


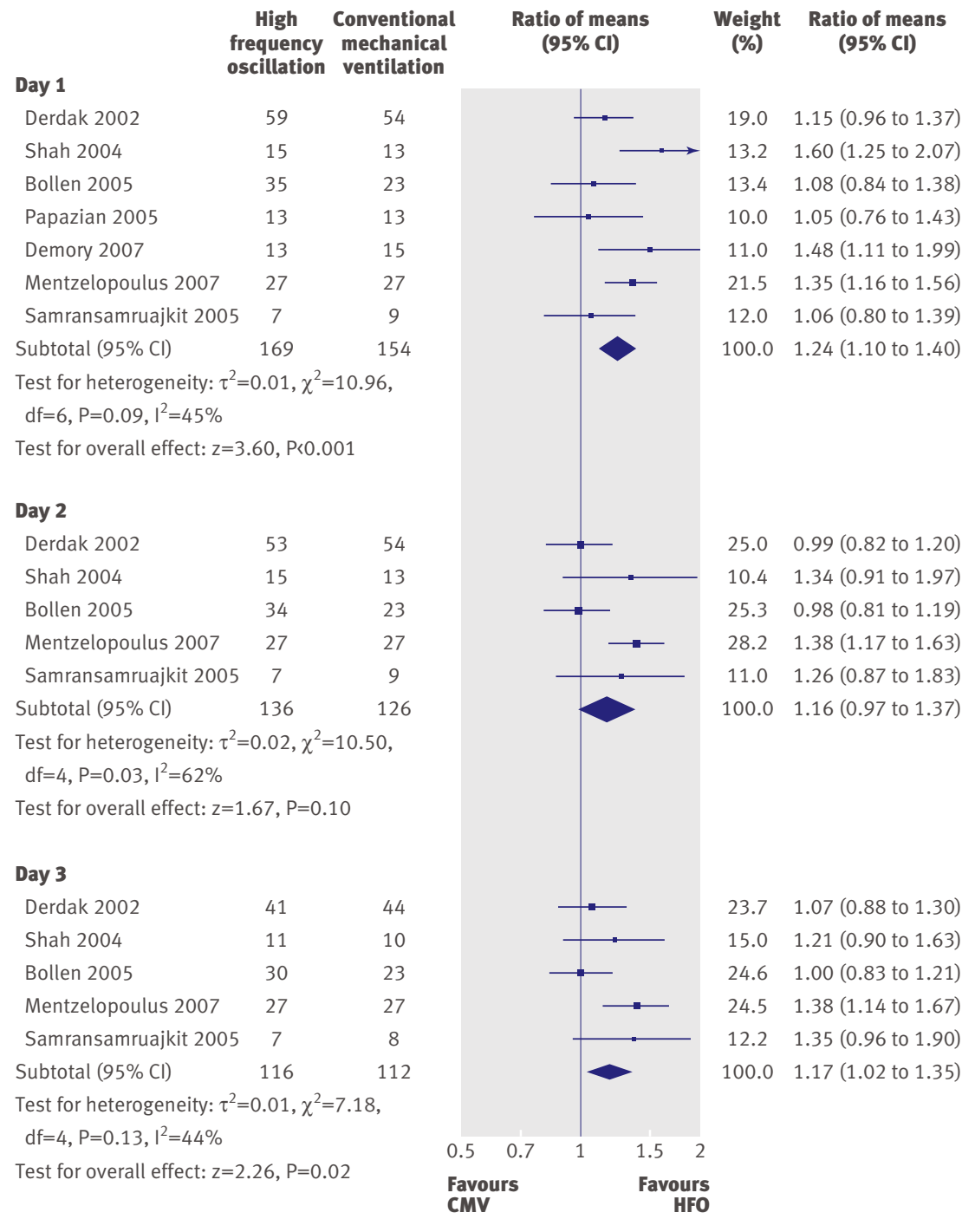

Fig $5 \mid \mathrm{PaO}_{2} / \mathrm{FiO}_{2}$ ratio on days 1-3. Ratio of means is mean $\mathrm{PaO}_{2} / \mathrm{FiO}_{2}$ in high frequency oscillation group divided by mean $\mathrm{PaO}_{2} / \mathrm{FiO}_{2}$ in conventional mechanical ventilation group

to treat analysis. One trial combined tracheal gas insufflation and recruitment manoeuvres with high frequency oscillation ${ }^{52}$; a randomised crossover trial showed that these co-interventions improve oxygenation. ${ }^{73}$ Results were similar when we excluded the data from this trial ${ }^{52}: 1.22(1.05$ to $1.40, \mathrm{P}=0.008$, $\left.\mathrm{I}^{2}=48 \%\right)$ on day $1,1.05$ (0.92 to $\left.1.19, \mathrm{P}=0.48, \mathrm{I}^{2}=6 \%\right)$ on day2, and 1.09 (0.97 to $\left.1.22, \mathrm{P}=0.14, \mathrm{I}^{2}=0 \%\right)$ on day 3 .

At 24,48 , and 72 hours, high frequency oscillation increased $\mathrm{PaO}_{2} / \mathrm{FiO}_{2}$ ratio by $16-24 \%$ relative to conventional mechanical ventilation and increased mean airway pressure by 22-33\%. Effects on the oxygenation index and $\mathrm{PaCO}_{2}$ did not significantly differ between high frequency oscillation and conventional ventilation. Heterogeneity was moderate for most analyses of physiological outcome $\left(\mathrm{I}^{2}=21-78 \%\right)$, but extreme $\left(\mathrm{I}^{2} \geq 90 \%\right)$ for the pooled analyses of $\mathrm{PaCO}_{2}$.

\section{Adverse events}

We found no significant differences (table 4) in the risk of barotrauma (six trials, $\mathrm{n}=365$ ), ${ }^{484951525455}$ hypotension (three trials, $\mathrm{n}=267),{ }^{484951}$ or endotracheal tube obstruction (four trials, n=246) (fig 6). ${ }^{51525455}$ Included studies varied in definitions of barotrauma: one study reported only pneumothorax, ${ }^{55}$ three studies reported any pulmonary air leak, ${ }^{515254}$ one study reported any pulmonary air leak that developed during protocol, ${ }^{48}$ and one study reported severe air leak resulting in treatment failure. ${ }^{49}$ Three studies reported intractable hypotension. ${ }^{484951}$ Two other trials reported transient hypotension related to a procedure, associated with either bronchoscopy on day 1 (1/15 in high frequency oscillation group and $0 / 13$ in conventional ventilation group $\left.^{55}\right)$, or recruitment manoeuvres on days 1-4 (11/ 27 and $8 / 27$, respectively ${ }^{52}$ ). Including these data minimally changed the pooled result (risk ratio $1.46,0.77$ to $\left.2.76, \mathrm{P}=0.24, \mathrm{I}^{2}=0 \%\right)$. Although four trials $(\mathrm{n}=246)$ reported on endotracheal tube obstruction, ${ }^{51525455}$ all events occurred in a single study, precluding a pooled analysis. There were no serious technical problems during high frequency oscillation in the three trials $(\mathrm{n}=98)$ that provided these data. ${ }^{52545}$ One trial $(n=54)$ reported minor technical problems, including over-efficiency of the humidifier that caused water accumulation in the circuit (number of instances not reported) and unintentional circuit leaks (five instances in 116 uninterrupted sessions lasting 6-48 hours). ${ }^{52}$

\section{DISCUSSION}

In patients with acute lung injury or ARDS, high frequency oscillation reduced hospital and 30 day mortality and decreased the risk of treatment failure compared with conventional mechanical ventilation. Although high frequency oscillation had no effect on the duration of mechanical ventilation, it improved oxygenation, as measured by the $\mathrm{PaO}_{2} / \mathrm{FiO}_{2}$ ratio, probably by increasing transpulmonary pressure and recruiting collapsed alveoli. There was no effect on oxygenation index because of the higher mean airway pressure during high frequency oscillation. Overall, high frequency oscillation had no effect on $\mathrm{PaCO}_{2}$, though the effects in individual trials were markedly inconsistent. Similarly, high frequency oscillation was not associated with an increase in adverse events.

\section{Strengths and limitations}

Our methods minimised bias by including a comprehensive literature search, abstracting data in triplicate, and using a predefined protocol outlining our hypotheses, methodological assessment of primary studies, and planned statistical analysis. We considered important clinical, physiological, and safety end points. Although blinding of patients, their families, and clinicians was not feasible, six of eight trials had high methodological quality and low risk of bias. Clinical outcomes were consistent across studies, including those that enrolled adults and children, strengthening the findings. 
Table 5 Physiological outcomes on days 1 to 3 after randomisation

\begin{tabular}{|c|c|c|c|c|c|}
\hline \multirow[b]{2}{*}{ Outcome } & \multirow{2}{*}{$\begin{array}{l}\text { No of } \\
\text { trials }\end{array}$} & \multirow{2}{*}{$\begin{array}{c}\text { No of } \\
\text { patients }\end{array}$} & \multicolumn{2}{|l|}{ Treatment effect } & \multirow{2}{*}{$\begin{array}{l}\text { Heterogeneity, } \\
\text { I2 (\%) }\end{array}$} \\
\hline & & & Ratio of means* $(95 \% \mathrm{Cl})$ & $P$ value & \\
\hline \multicolumn{6}{|l|}{ Day 1 (24 hours) } \\
\hline $\mathrm{PaO}_{2} / \mathrm{FiO}_{2}$ & 7 & 323 & 1.24 (1.11 to 1.40$)$ & $<0.001$ & 45 \\
\hline Mean airway pressure & 7 & 331 & 1.33 (1.27 to 1.40$)$ & $<0.001$ & 21 \\
\hline Oxygenation index & 6 & 294 & 1.11 (0.97 to 1.26$)$ & 0.12 & 38 \\
\hline $\mathrm{PaCO}_{2}$ & 6 & 300 & 0.91 (0.78 to 1.07 ) & 0.25 & 91 \\
\hline \multicolumn{6}{|l|}{ Day 2 (48 hours) } \\
\hline $\mathrm{PaO}_{2} / \mathrm{FiO}_{2}$ & 5 & 262 & $1.16(0.97$ to 1.37$)$ & 0.10 & 62 \\
\hline Mean airway pressure & 5 & 262 & $1.26(1.16$ to 1.37$)$ & $<0.001$ & 58 \\
\hline Oxygenation index & 5 & 259 & $1.07(0.92$ to 1.24$)$ & 0.38 & 39 \\
\hline $\mathrm{PaCO}_{2}$ & 5 & 263 & $0.87(0.72$ to 1.06$)$ & 0.16 & 95 \\
\hline \multicolumn{6}{|l|}{ Day 3 (72 hours) } \\
\hline $\mathrm{PaO}_{2} / \mathrm{FiO}_{2}$ & 5 & 228 & 1.17 (1.02 to 1.35$)$ & 0.02 & 44 \\
\hline Mean airway pressure & 5 & 236 & $1.22(1.07$ to 1.39$)$ & 0.003 & 78 \\
\hline Oxygenation index & 5 & 228 & 1.07 (0.88 to 1.29 ) & 0.51 & 58 \\
\hline $\mathrm{PaCO}_{2}$ & 6 & 267 & 0.98 (0.84 to 1.14$)$ & 0.78 & 90 \\
\hline
\end{tabular}

$\mathrm{PaO}_{2} / \mathrm{FiO}_{2}=$ ratio of arterial partial pressure of oxygen to fraction of inspired oxygen; $\mathrm{PaCO}_{2}=$ arterial partial pressure of carbon dioxide.

* Mean value in high frequency oscillation group divided by mean value in conventional ventilation group. Random effects models used for all meta-analyses.

The mortality benefit of high frequency oscillation could be overestimated because the control group in three studies, ${ }^{48951}$ including the largest trial, ${ }^{51}$ which had the highest weighting in the pooled analysis, was exposed to higher tidal volumes $(>6-8 \mathrm{ml} / \mathrm{kg}$ predicted body weight) than currently recommended. ${ }^{15} \mathrm{~A}$ subgroup analysis, however, showed a similar benefit in trials that implemented lower tidal volumes in the control group. Alternatively, the higher rate of crossovers because of treatment failure in patients randomised to conventional ventilation might have reduced the measured effect of high frequency oscillation on mortality. In two studies that enrolled $30 \%$ of patients included in our review, ${ }^{4849}$ more than $10 \%$ crossed over from their assigned mode of ventilation, highlighting an important methodological challenge in clinical trials of high frequency oscillation. Another opportunity to improve the success of future trials of high frequency oscillation would be to adopt consistent protocols for its optimal application. ${ }^{56}$ In our review, only one study routinely applied recruitment manoeuvres as part of the high frequency oscillation technique, ${ }^{52}$ and no trial attempted to maximise the frequency of oscillation to obtain the smallest possible tidal volume. ${ }^{57}$

Though our primary analysis showed improved hospital or 30 day mortality, it was based on relatively few patients and outcome events and has wide confidence intervals. Similarly, for the meta-analysis of treatment failure, when the two patients randomised to conventional ventilation in one trial ${ }^{52}$ who were only briefly crossed over to high frequency oscillation were not counted as treatment failures, the pooled result was no longer significant $(\mathrm{P}=0.06)$. The specific events included in the definition of treatment failure varied across trials, none of which reported blinding of outcome assessors or independent adjudication of treatment failure. ${ }^{4849515254}$ The effects of high frequency oscillation on clinical outcomes seemed to be consistent, but tests for heterogeneity are underpowered when there are few trials. Limited data precluded subgroup analyses based on degree of hypoxaemia and analyses of longer term mortality and health related quality of life, although the finding of a non-significant 21\% relative risk reduction in six month mortality in one trial ${ }^{51}$ was consistent with the effect on hospital or 30 day mortality. We found moderate to high heterogeneity for physiological end points, limiting their interpretability. Because of limited data, we were unable to analyse duration of mechanical ventilation separately for survivors and non-survivors to address the possibility that differences in early mortality could drive overall differences in duration of mechanical ventilation. Thus, although our findings support high frequency oscillation as a promising treatment for acute lung injury and ARDS, the overall quality of the evidence is moderate for the most important clinical outcomes,${ }^{41}$ and ongoing trials might affect these findings.

\section{Findings in relation to other studies}

Our findings differ from those of a Cochrane review in 2004 , which did not find reduced mortality or treatment failure or improved $\mathrm{PaO}_{2} / \mathrm{FiO}_{2} \cdot{ }^{28} \mathrm{We}$ included six additional trials of high frequency oscillation and unpublished data provided by primary investigators, which generated additional statistical power and more precise estimates of treatment effects.

The improvements we observed in $\mathrm{PaO}_{2} / \mathrm{FiO}_{2}$ are consistent with those in observational studies. ${ }^{25-27}$ Although high frequency oscillation increased $\mathrm{PaO}_{2} /$ $\mathrm{FiO}_{2}$ compared with conventional ventilation, there was no difference in the oxygenation index (defined as $100 \times$ mean airway pressure $/\left(\mathrm{PaO}_{2} / \mathrm{FiO}_{2}\right.$ ratio $\left.)\right)$ because of higher mean airway pressure applied during high frequency oscillation. Although high mean airway pressure during conventional ventilation is commonly believed to harm the lungs, ${ }^{10}$ the importance of higher mean airway pressure during high frequency oscillation is unclear because of its incompletely characterised association with alveolar pressure, which is a more important determinant of lung injury in patients with ARDS. Direct comparisons of mean airway pressure and oxygenation index between high frequency oscillation and conventional ventilation might not be valid because mean airway pressures measured in the trachea during high frequency oscillation are $6-8 \mathrm{~cm} \mathrm{H}_{2} \mathrm{O}$ lower than values displayed on the ventilator, in contrast with conventional ventilation. ${ }^{58}$

The decreased risk of mortality in patients who received high frequency oscillation is consistent with results of experimental studies in animals, showing that histological alveolar overdistension is reduced by high frequency oscillation compared with conventional mechanical ventilation, ${ }^{59}$ possibly because tidal volumes are smaller. ${ }^{57}$ Although improved oxygenation might not always be associated with improved clinical outcomes in ARDS, ${ }^{6061}$ from a clinical perspective high frequency oscillation allows higher mean 


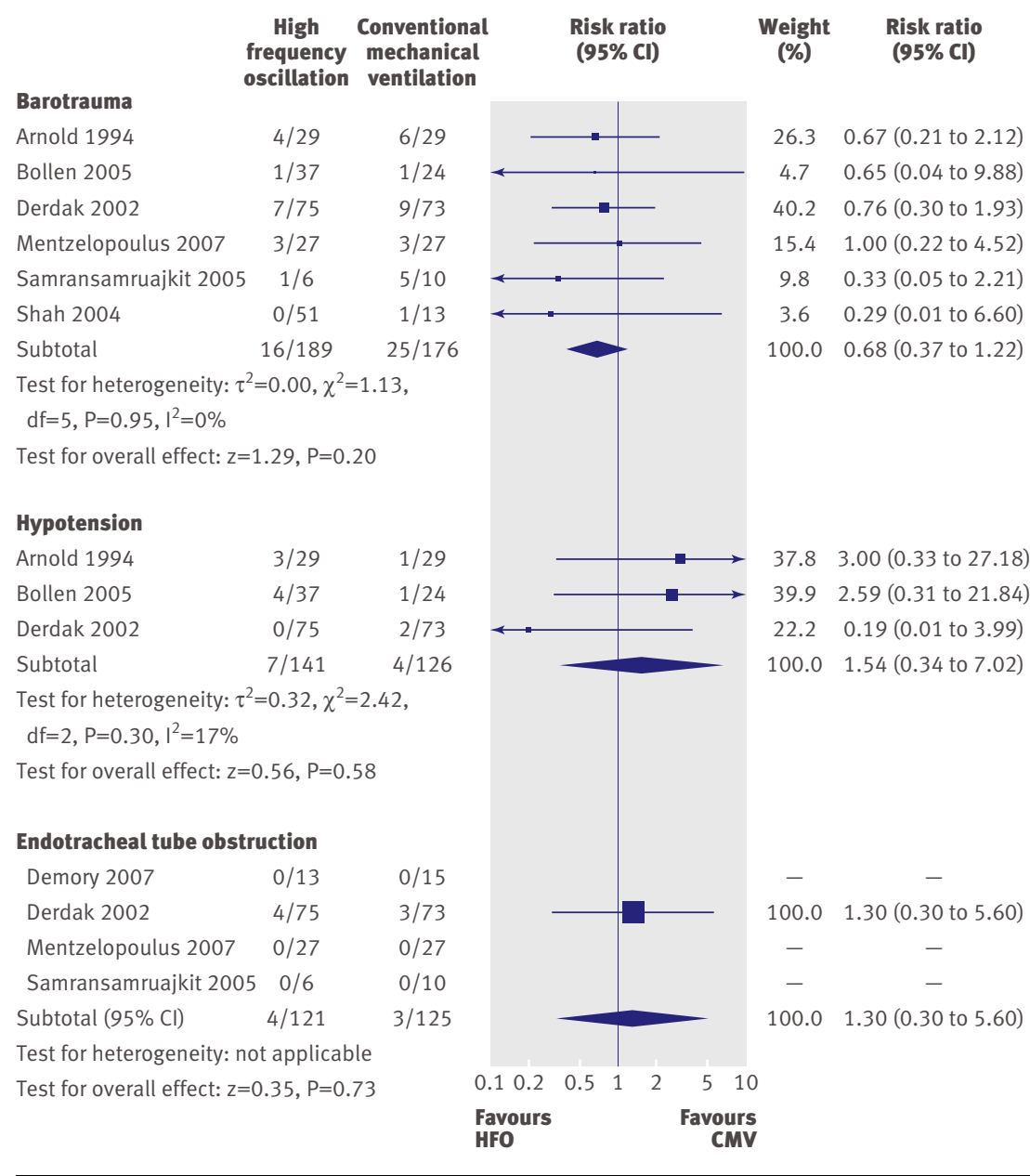

Fig 6 | Adverse events in patients with acute lung injury/acute respiratory distress syndrome allocated to high frequency oscillation or conventional mechanical ventilation

airway pressures without increasing barotrauma and might therefore safely recruit collapsed lung. ${ }^{62}$ Increased lung recruitment and reduction of alveolar overdistension could reduce ventilator induced lung injury $^{1062}$ and provide a biological rationale for improved clinical outcomes.

\section{Implications for practice}

The risk of death in patients with ARDS is high ${ }^{12}$ and seems stable over the past decade. ${ }^{2}$ In our review, the

\section{WHAT IS ALREADY KNOWN ON THIS TOPIC}

Some centres routinely use high frequency oscillation to support oxygenation in adults and children with acute respiratory distress syndrome (ARDS), although there is no clear evidence that it reduces mortality

An earlier systematic review found only two randomised trials and could not draw definitive conclusions regarding efficacy

\section{WHAT THIS STUDY ADDS}

In an updated review of eight randomised controlled trials, pooled results suggest that high frequency oscillation improves oxygenation and reduces the risk of treatment failure (refractory hypoxaemia, hypercapnoea, hypotension, or barotrauma) as well as hospital or 30 day mortality compared with conventional mechanical ventilation in patients with ARDS median mortality in the control group was $48 \%$. As shown in a recent observational study of patients with H1N1 flu, many patients with severe ARDS required inhaled nitric oxide, prone positioning, high frequency oscillation, or extracorporeal membrane oxygenation, usually for refractory hypoxaemia. ${ }^{29}$ These treatments have different risk-benefit profiles. ${ }^{63-66}$ Inhaled nitric oxide is expensive, has not been shown to reduce mortality, and could cause harm. ${ }^{65}$ Extracorporeal membrane oxygenation might reduce mortality but is a specialised technique that is not widely available ${ }^{66}$ and requires systemic anticoagulation, which increases the risk of morbidity and mortality related to bleeding. ${ }^{67}$ Mechanical ventilation in the prone position reduces mortality in severely hypoxaemic patients $^{64}$ and is inexpensive, but complications ${ }^{68}$ and interference with other aspects of patient care might limit its application. ${ }^{6970}$ Our review suggests that high frequency oscillation is a safe and effective alternative to conventional ventilation in patients with ARDS, at least in centres proficient with its use.

\section{Future research}

The limitations of current data will be addressed by two ongoing trials of high frequency oscillation compared with conventional ventilation (see appendix 1 on bmj.com). Each trial applies a lung protective approach to the control group, and collectively they will enrol more than 2000 patients. In the pilot phase of one of these trials, crossovers between randomly assigned ventilation strategies outside of protocol were infrequent. ${ }^{71}$ These trials will therefore compare high frequency oscillation with best current conventional ventilation and will provide more precise estimates of treatment effect.

\section{Conclusion}

In summary, based on the available data, high frequency oscillation might reduce mortality in patients with ARDS compared with conventional ventilation and is unlikely to cause harm. It improves the $\mathrm{PaO}_{2} /$ $\mathrm{FiO}_{2}$ ratio by increasing the mean airway pressure but not the oxygenation index. Clinicians who currently use or are considering high frequency oscillation to treat ARDS can be reassured by these results. Completion of ongoing multicentre randomised controlled trials will provide more definitive data on mortality and safety for this intervention.

We thank all primary investigators who provided additional data for this review: Steven Derdak and Tom Bachman; Casper Bollen; Spyros Mentzelopoulos; Rujipat Samransamruajkit; and Sanjoy Shah. Preliminary results from this study were presented at the Society of Critical Care Medicine 2008 annual congress. ${ }^{72}$

Contributors: All authors contributed to study concept and design, revised the manuscript for important intellectual content, and approved the final version. SS conceived the study, acquired data, analysed and interpreted data, and drafted the manuscript. MS, JOF, and NKJA acquired, analysed, and interpreted data. MOM, NDF, and HW interpreted data. NKJA and JOF contributed equally to this study. SS, JOF, and NKJA are guarantors.

Funding: The study received no specific funding. JOF is supported by a Clinician-Scientist award from the Canadian Institutes of Health Research (CIHR). NDF is supported by a CIHR New Investigator Award. CIHR had no 
involvement in the design and conduct of the study; collection, management, analysis, and interpretation of the data; and preparation, review, or approval of the manuscript.

Competing interests: All authors have completed the Unified Competing Interest form at www.icmje.org/coi_disclosure.pdf (available on request from the corresponding author) and declare that all authors had: (1) No financial support for the submitted work from anyone other than their employer; (2) No financial relationships with commercial entities that might have an interest in the submitted work; (3) No spouses, partners, or children with relationships with commercial entities that might have an interest in the submitted work; (4) The following non-financial interests relevant to the submitted work: MOM and NDF are primary investigators and JOF and NKJA are co-investigators for the ongoing Canadian Institutes of Health Research (CIHR) funded OSCILLATE study. CareFusion (formerly SensorMedics) is providing study oscillators to some of the hospitals involved in the OSCILLATE study for the duration of the study. Ethical approval: Not required.

Data sharing: The protocol for the systematic review and dataset (RevMan 5.0 format) are available by request to the corresponding author.

1 Rubenfeld GD, Caldwell E, Peabody E, Weaver J, Martin DP, Neff M, et al. Incidence and outcomes of acute lung injury. $N$ Engl $J$ Med 2005;353:1685-93.

2 Phua J, Badia JR, Adhikari NK, Friedrich JO, Fowler RA, Singh JM, et al. Has mortality from acute respiratory distress syndrome decreased over time?: A systematic review. Am J Respir Crit Care Med 2009;179:220-7.

3 Angus DC, Musthafa AA, Clermont G, Griffin MF, Linde-Zwirble WT, Dremsizov T, et al. Quality-adjusted survival in the first year after the acute respiratory distress syndrome. Am J Respir Crit Care Med 2001:163:1389-94.

4 Herridge MS, Cheung AM, Tansey CM, Matte-Martyn A, Diaz-Granados N, Al-Saidi F, et al. One-year outcomes in survivors of the acute respiratory distress syndrome. N Engl J Med 2003;348:683-93.

5 Cheung AM, Tansey CM, Tomlinson G, Diaz-Granados N, Matte A, Barr A, et al. Two-year outcomes, health care use, and costs of survivors of acute respiratory distress syndrome. Am J Respir Crit Care Med 2006;174:538-44

6 Artigas A, Bernard GR, Carlet J, Dreyfuss D, Gattinoni L, Hudson L, et al. The American-European Consensus Conference on ARDS, part 2: Ventilatory, pharmacologic, supportive therapy, study design strategies, and issues related to recovery and remodeling. Acute respiratory distress syndrome. Am / Respir Crit Care Med 1998;157:1332-47.

7 Dreyfuss D, Soler P, Basset G, Saumon G. High inflation pressure pulmonary edema. Respective effects of high airway pressure, high tidal volume, and positive end-expiratory pressure. Am Rev Respir Dis 1988;137:1159-64.

8 Muscedere JG, Mullen JB, Gan K, Slutsky AS. Tidal ventilation at low airway pressures can augment lung injury. Am J Respir Crit Care Med 1994;149:1327-34.

9 Gattinoni L, Pesenti A. The concept of "baby lung." Intensive Care Med 2005;31:776-84.

10 Ranieri VM, Suter PM, Tortorella C, De Tullio R, Dayer JM, Brienza A, et al. Effect of mechanical ventilation on inflammatory mediators in patients with acute respiratory distress syndrome: a randomized controlled trial. JAMA 1999;282:54-61.

11 Amato MB, Barbas CS, Medeiros DM, Magaldi RB, Schettino GP, Lorenzi-Filho G, et al. Effect of a protective-ventilation strategy on mortality in the acute respiratory distress syndrome. $N$ Engl J Med 1998;338:347-54.

12 Villar J, Kacmarek RM, Perez-Mendez L, Aguirre-Jaime A. A high positive end-expiratory pressure, low tidal volume ventilatory strategy improves outcome in persistent acute respiratory distress syndrome: a randomized, controlled trial. Crit Care Med 2006;34:1311-8

13 Mercat A, Richard JC, Vielle B, Jaber S, Osman D, Diehl JL, et al. Positive end-expiratory pressure setting in adults with acute lung injury and acute respiratory distress syndrome: a randomized controlled trial. JAMA 2008;299:646-55.

14 Meade MO, Cook DJ, Guyatt GH, Slutsky AS, Arabi YM, Cooper DJ, et al. Ventilation strategy using low tidal volumes, recruitment maneuvers, and high positive end-expiratory pressure for acute lung injury and acute respiratory distress syndrome: a randomized controlled trial. JAMA 2008;299:637-45.

15 Acute Respiratory Distress Syndrome Network. Ventilation with lowe tidal volumes as compared with traditional tidal volumes for acute lung injury and the acute respiratory distress syndrome. N EnglJ Med 2000;342:1301-8
16 Brochard L, Roudot-Thoraval F, Roupie E, Delclaux C, Chastre J, Fernandez-Mondejar $E$, et al. Tidal volume reduction for prevention of ventilator-induced lung injury in acute respiratory distress syndrome. The Multicenter Trail Group on Tidal Volume reduction in ARDS. Am Respir Crit Care Med 1998;158:1831-8.

17 Stewart TE, Meade MO, Cook DJ, Granton JT, Hodder RV, Lapinsky SE, et al. Evaluation of a ventilation strategy to prevent barotrauma in patients at high risk for acute respiratory distress syndrome. Pressure- and Volume-Limited Ventilation Strategy Group. N Engl J Med 1998;338:355-61.

18 Slutsky AS, Drazen JM. Ventilation with small tidal volumes. N Engl J Med 2002;347:630-1.

19 Rimensberger PC. ICU cornerstone: high frequency ventilation is here to stay. Crit Care 2003;7:342-4.

20 Mehta S, Granton J, MacDonald RJ, Bowman D, Matte-Martyn A, Bachman T, et al. High-frequency oscillatory ventilation in adults: the Toronto experience. Chest 2004;126:518-27.

21 Finkielman JD, Gajic O, Farmer JC, Afessa B, Hubmayr RD. The initial Mayo Clinic experience using high-frequency oscillatory ventilation for adult patients: a retrospective study. BMC Emerg Med 2006;6:2.

22 Chan KP, Stewart TE. Clinical use of high-frequency oscillatory ventilation in adult patients with acute respiratory distress syndrome. Crit Care Med 2005;33:S170-4.

23 Kacmarek RM. Counterpoint: high-frequency ventilation is not the optimal physiological approach to ventilate ARDS patients. J App Physiol 2008;104:1232-5.

24 Ferguson ND, Slutsky AS. Point: high-frequency ventilation is the optimal physiological approach to ventilate ARDS patients. J App Physiol 2008;104:1230-1.

25 Ferguson ND, Chiche JD, Kacmarek RM, Hallett DC, Mehta S, Findlay GP, et al. Combining high-frequency oscillatory ventilation and recruitment maneuvers in adults with early acute respiratory distress syndrome: the treatment with oscillation and an open lung strategy (TOOLS) trial pilot study. Crit Care Med 2005;33:479-86.

26 Fort P, Farmer C, Westerman J, Johannigman J, Beninati W, Dolan S, et al. High-frequency oscillatory ventilation for adult respiratory distress syndrome-a pilot study. Crit Care Med 1997;25:937-47.

27 Mehta S, Lapinsky SE, Hallett DC, Merker D, Groll RJ, Cooper AB, et al. Prospective trial of high-frequency oscillation in adults with acute respiratory distress syndrome. Crit Care Med 2001:29:1360-9.

28 Wunsch H, Mapstone J. High-frequency ventilation versus conventional ventilation for treatment of acute lung injury and acute respiratory distress syndrome. Cochrane Database Syst Rev 2004;(1):CD004085.

29 Kumar A, Zarychanski R, Pinto R, Cook DJ, Marshall J, Lacroix J, et al. Critically ill patients with 2009 influenza $\mathrm{A}(\mathrm{H} 1 \mathrm{N1})$ infection in Canada. JAMA 2009;302:1872-9.

30 Dominguez-Cherit G, Lapinsky SE, Macias AE, Pinto R, Espinosa-Perez L, de la Torre A, et al. Critically ill patients with 2009 influenza $\mathrm{A}(\mathrm{H} 1 \mathrm{~N} 1)$ in Mexico. JAMA 2009;302:1880-7.

31 Meade MO, Richardson WS. Selecting and appraising studies for a systematic review. Ann Intern Med 1997;127:531-7.

32 Egger M, Zellweger-Zahner T, Schneider M, Junker C, Lengeler C, Antes $\mathrm{G}$. Language bias in randomised controlled trials published in English and German. Lancet 1997;350:326-9.

33 Berlin JA. Does blinding of readers affect the results of metaanalyses? University of Pennsylvania meta-analysis blinding study group. Lancet 1997;350:185-6.

34 Miller MP, Sagy M. Pressure characteristics of mechanical ventilation and incidence of pneumothorax before and after the implementation of protective lung strategies in the management of pediatric patients with severe ARDS. Chest 2008;134:969-73.

35 Hanson $\mathrm{JH}$, Flori $\mathrm{H}$. Application of the acute respiratory distress syndrome network low-tidal volume strategy to pediatric acute lung injury. Respir Care Clin N Am 2006;12:349-57.

36 Albuali WH, Singh RN, Fraser DD, Seabrook JA, Kavanagh BP, Parshuram CS, et al. Have changes in ventilation practice improved outcome in children with acute lung injury? Pediatr Crit Care Med 2007;8:324-30.

37 Chalmers TC, Celano P, Sacks HS, Smith H Jr. Bias in treatment assignment in controlled clinical trials. $N$ Engl J Med 1983;309:1358-61.

38 Schulz KF, Chalmers I, Hayes RJ, Altman DG. Empirical evidence of bias. Dimensions of methodological quality associated with estimates of treatment effects in controlled trials. JAMA 1995;273:408-12.

39 Montori VM, Devereaux PJ, Adhikari NK, Burns KE, Eggert CH, Briel M et al. Randomized trials stopped early for benefit: a systematic review. JAMA 2005;294:2203-9.

40 Cochrane Collaboration's tool for assessing risk of bias. In: Higgins JPT, Green S, eds. Cochrane Handbook for Systematic Reviews of Interventions. Version 5.0.2 [updated September 2009]. Cochrane Collaboration, 2009. www.cochrane-handbook.org.

41 Schunemann HJ, Oxman AD, Brozek J, Glasziou P, Jaeschke R, Vist GE, et al. Grading quality of evidence and strength of 
recommendations for diagnostic tests and strategies. BMJ 2008;336:1106-10.

42 Cartotto R, Ellis S, Gomez M, Cooper A, Smith T. High frequency oscillatory ventilation in burn patients with the acute respiratory distress syndrome. Burns 2004;30:453-63.

43 Friedrich JO, Adhikari NK, Beyene J. The ratio of means method as an alternative to mean differences for analyzing continuous outcome variables in meta-analysis: a simulation study. BMC Med Res Methodol 2008;8:32.

44 Higgins JP, Thompson SG. Quantifying heterogeneity in a metaanalysis. Stat Med 2002;21:1539-58.

45 Higgins JP, Thompson SG, Deeks JJ, Altman DG. Measuring inconsistency in meta-analyses. BM/ 2003;327:557-60.

46 Begg CB, Mazumdar M. Operating characteristics of a rank correlation test for publication bias. Biometrics 1994;50:1088-101.

47 Macaskill P, Walter SD, Irwig L. A comparison of methods to detect publication bias in meta-analysis. Stat Med 2001;20:641-54.

48 Arnold JH, Hanson JH, Toro-Figuero LO, Gutierrez J, Berens RJ, Anglin DL. Prospective, randomized comparison of high-frequency oscillatory ventilation and conventional mechanical ventilation in pediatric respiratory failure. Crit Care Med 1994;22:1530-9.

49 Bollen CW, van Well GT, Sherry T, Beale RJ, Shah S, Findlay G, et al. High frequency oscillatory ventilation compared with conventional mechanical ventilation in adult respiratory distress syndrome: a randomized controlled trial. Crit Care 2005;9:R430-9.

50 Demory D, Michelet P, Arnal JM, Donati S, Forel JM, Gainnier M, et al. High-frequency oscillatory ventilation following prone positioning prevents a further impairment in oxygenation. Crit Care Med 2007;35:106-11.

51 Derdak S, Mehta S, Stewart TE, Smith T, Rogers M, Buchman TG, et al. High-frequency oscillatory ventilation for acute respiratory distress syndrome in adults: a randomized, controlled trial. Am J Respir Crit Care Med 2002;166:801-8.

52 Mentzelopoulos SD, Malachias S, Tzoufi M, Markaki V, Zervakis D, Pitaridis $M$, et al. High frequency oscillation and tracheal gas insufflation for severe acute respiratory distress syndrome. Intensive Care Med 2007;33:S142.

53 Papazian L, Gainnier M, Marin V, Donati S, Arnal JM, Demory D, et al. Comparison of prone positioning and high-frequency oscillatory ventilation in patients with acute respiratory distress syndrome. Crit Care Med 2005;33:2162-71.

54 Samransamruajkit R, Prapphal N, Deelodegenavong J, Poovorawan Y. Plasma soluble intercellular adhesion molecule-1 (sICAM-1) in pediatric ARDS during high frequency oscillatory ventilation: a predictor of mortality. Asian Pac J Allergy Immuno 2005;23:181-8

55 Shah SB, Findlay GP, Jackson SK, Smithies MN. Prospective study comparing HFOV versus CMV in patients with ARDS. Intensive Care Med 2004;30:S84

56 Fessler HE, Derdak S, Ferguson ND, Hager DN, Kacmarek RM, Thompson BT, et al. A protocol for high-frequency oscillatory ventilation in adults: results from a roundtable discussion. Crit Care Med 2007;35:1649-54

57 Hager DN, Fessler HE, Kaczka DW, Shanholtz CB, Fuld MK, Simon BA, et al. Tidal volume delivery during high-frequency oscillatory ventilation in adults with acute respiratory distress syndrome. Crit Care Med 2007;35:1522-9.

58 Muellenbach RM, Kredel M, Said HM, Klosterhalfen B, Zollhoefer B, Wunder $C$, et al. High-frequency oscillatory ventilation reduces lung inflammation: a large-animal 24-h model of respiratory distress. Intensive Care Med 2007;33:1423-33.

59 Sedeek KA, Takeuchi M, Suchodolski K, Vargas SO, Shimaoka M, Schnitzer JJ, et al. Open-lung protective ventilation with pressure control ventilation, high-frequency oscillation, and intratracheal pulmonary ventilation results in similar gas exchange, hemodynamics, and lung mechanics. Anesthesiology 2003;99:1102-11.

60 Slutsky AS. Improving outcomes in critically ill patients: the seduction of physiology. JAMA 2009;302:2030-2.

61 Bernard GR. PEEP guided by esophageal pressure-any added value? N Engl J Med 2008;359:2166-8.

62 Gattinoni L, Caironi P, Cressoni M, Chiumello D, Ranieri VM, Quintel $M$, et al. Lung recruitment in patients with the acute respiratory distress syndrome. N Engl J Med 2006;354:1775-86.

63 Sud S, Sud M, Friedrich JO, Adhikari NK. Effect of prone positioning in patients with acute respiratory distress syndrome and high simplified acute physiology score II. Crit Care Med 2008;36:2711-2 (author reply 2712-3).

64 Sud S, Friedrich JO, Taccone P, Polli F, Adhikari NK, Latini R, et al. Prone ventilation reduces mortality in patients with acute respiratory failure and severe hypoxemia: systematic review and meta-analysis. Intensive Care Med 2010;36:585-99.

65 Adhikari NK, Burns KE, Friedrich JO, Granton JT, Cook DJ, Meade MO. Effect of nitric oxide on oxygenation and mortality in acute lung injury: systematic review and meta-analysis. BMJ 2007;334:779.

66 Peek GJ, Mugford M, Tiruvoipati R, Wilson A, Allen E, Thalanany MM, et al. Efficacy and economic assessment of conventional ventilatory support versus extracorporeal membrane oxygenation for severe adult respiratory failure (CESAR): a multicentre randomised controlled trial. Lancet 2009;374:1351-63.

67 ANZICS H1N1 ECMO Study (Australia and New Zealand Extracorporeal Membrane Oxygenation Influenza) Investigators. Extracorporeal membrane oxygenation for 2009 influenza A(H1N1) acute respiratory distress syndrome. JAMA 2009;302:1888-95.

68 Taccone P, Pesenti A, Latini R, Polli F, Vagginelli F, Mietto C, et al. Prone positioning in patients with moderate and severe acute respiratory distress syndrome: a randomized controlled trial. JAMA 2009;302:1977-84.

69 Leonet S, Fontaine C, Moraine JJ, Vincent JL. Prone positioning in acute respiratory failure: survey of Belgian ICU nurses. Intensive Care Med 2002;28:576-80.

70 Bein T, Ritzka M, Schmidt F, Taeger K. Positioning therapy in intensive care medicine in Germany. Results of a national survey [in German]. Anaesthesist 2007;56:226-31.

71 Meade MO, Cook DJ, Mehta S, Arabi YM, Keenan S, Ronco JJ, et al. A multicentre pilot randomized trial of high frequency oscillation in acute respiratory distress syndrome. Am J Respir Crit Care Med 2009;179:A1559.

72 Sud S, Adhikari N, Ferguson ND, Friedrich JO, Sud M, Meade MO. High-frequency oscillatory ventilation for ARDS: a meta-analysis. Crit Care Med 2007;35:A225.

73 Mentzelopoulos SD, Roussos C, Koutsoukou A, Sourlas S, Malachias S, Lachana A, et al. Acute effects of combined highfrequency oscillation and tracheal gas insufflation in severe acute respiratory distress syndrome. Crit Care Med 2007;35:1500-8.

Accepted: 7 April 2010 